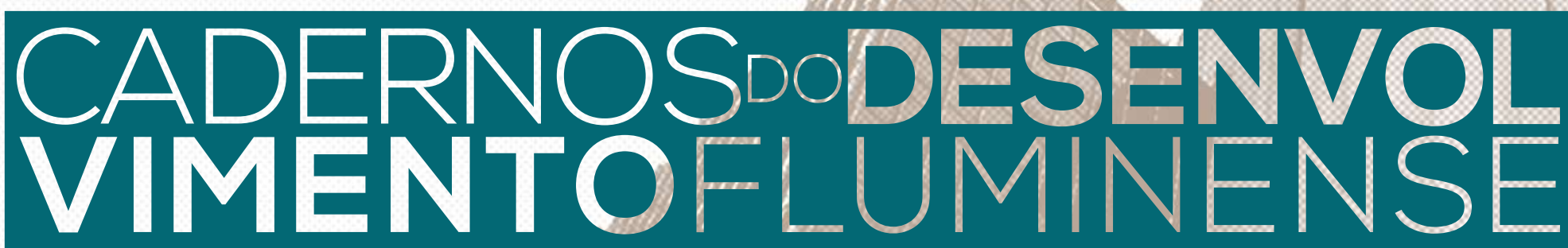

16

ANO $2019 \mid 1^{\circ}$ semestre

- Especialização produtiva - reflexos sobre o

desenvolvimento do estado do Rio de Janeiro;

- Relação entre renda petrolífera e melhoria na

qualidade de vida por municípios

confrontantes da Bacia de Campos;

- Desafios à gestão, ao desenvolvimento sustentável em Miracema;

- Inovação e Desenvolvimento Regional - uma análise sobre a produção científica da Universidade Estadual do Norte Fluminense e sua potencial contribuição para a sociedade;

- Perfil socioeconômico de feirantes do mercado municipal de Campos dos Goytacazes;

- Casa popular própria - ilusão ou solução;

- Capilaridade territorial na provisão de medicamentos básicos no estado do Rio de Janeiro;

- NudgeRio um caso de aplicação de Ciência Comportamental às Políticas Públicas;

- Mulher, política e cidade - reflexões analíticas.
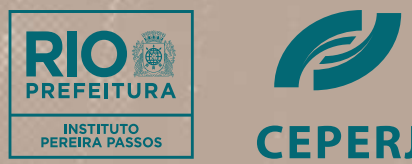


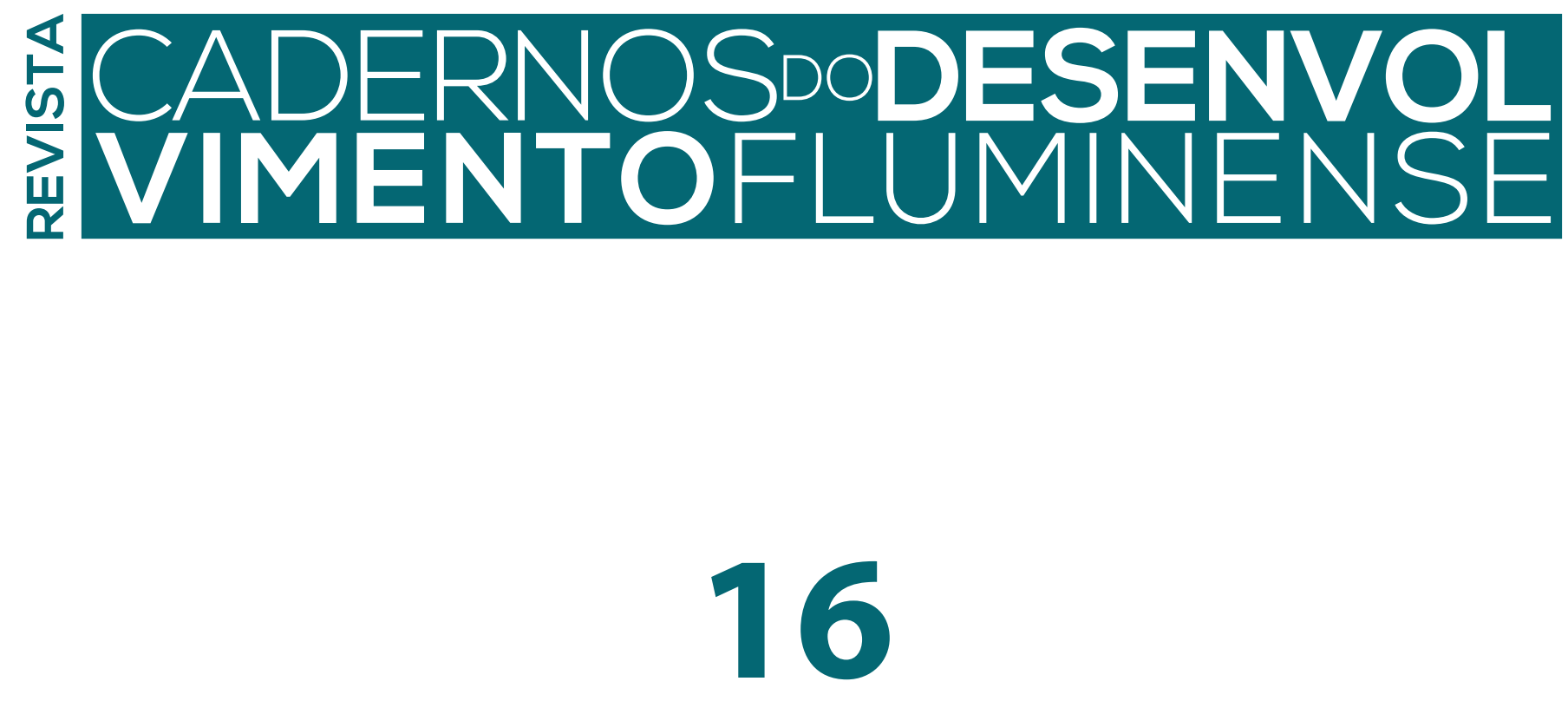

ANO 2019 $\mid 1^{\circ}$ semestre 
FUNDAÇÃO CENTRO ESTADUAL DE ESTATÍSTICAS, PESQUISAS E FORMAÇÃO

DE SERVIDORES PÚBLICOS DO RIO DE JANEIRO — CEPERJ

PRESIDÊNCIA

Pedro Castilho

ESCOLA DE GESTÃO E POLÍTICAS PÚBLICAS

Homero de Araújo Torres

CENTRO DE ESTATÍSTICAS, ESTUDOS E PESQUISAS

Fabio Odilon Alves Gomes

DIRETORIA DE CONCURSOS E PROCESSOS SELETIVOS

Lisandro Junior

DIRETORIA DE COOPERAÇÃO TÉCNICA E DES. INSTITUCIONAL

Tatiani Lisboa

DIRETORIA ADMINISTRATIVA E FINANCEIRA

Marcelo Serrano Peixoto

INSTITUTO PEREIRA PASSOS — IPP

DIRETOR-PRESIDENTE

Mauro Osorio

COORDENADOR TÉCNICO DE INFORMAÇÕES DA CIDADE

Carlos Krykhtyne

COORDENADORA TÉCNICA DE PROJETOS ESPECIAIS

Andrea Pulici

COORDENADOR DE COMUNICAÇÃO

Bruno Filippo 


\section{Editores}

EDITORES CIENTÍFICOS

Jorge Britto • UFF

Lia Hasenclever • Instituto de Economia - UFRJ

EDITOR EXECUTIVO

Bruno Filippo • IPP

\section{CONSELHO EDITORIAL}

Bruno Leonardo Barth Sobral • Faculdade de Ciências Econômicas - UERJ

Carlos Antonio Brandão • Inst. de Pesquisa e Planejamento Urbano e Regional - UFRJ

Fabiano Guilherme Mendes Santos • Instituto de Estudos Sociais e Políticos - UERJ

Glaucio José Marafon • Instituto de Geografia - UERJ

Jorge Nogueira de Paiva Britto • Faculdade de Economia - UFRJ

José Luis Vianna da Cruz • Centro de Pesquisa Candido Mendes - UCM

Lia Hasenclever • Inst. de Economia - UFRJ / Universidade Cândido Mendes

Campos - UCAM Campos

Luis Fernando Valverde Salandía • Instituto Pereira Passos

Luiz Martins de Melo • Instituto de Economia - UFRJ

Maria Alice Rezende de Carvalho • Depto. de Ciências Sociais - PUC RJ

Maria Lucia Teixeira Werneck Vianna • Instituto de Economia - UFRJ

Maria Helena de Macedo Versiani • Instituto Brasileiro de Museus

Marieta de Moraes Ferreira • Fundação Getúlio Vargas

Mauro Osorio • Faculdade Nacional de Direito - UFRJ

wMiguel Antonio Pinho Bruno - Escola Nacional de Ciências Estatísticas - IBGE /Fac. de Ciên-

cias Econômicas - UERJ / Mackenzie Rio

Nelson de Castro Senra • Escola Nacional de Ciências Estatísticas - IBGE

Paulo Alcântara • Universidade Cândido Mendes - UCAM

Paulo Knauss Mendonça • Depto. de História - UFF

Pedro Abramo • Instituto de Pesquisa e Planejamento Urbano Regional - UFRJ

Renata Lèbre La Rovere • Instituto de Economia - UFRJ

Roberto de Andrade Medronho • Instituto de Estudos em Saúde Coletiva - UFRJ

Rosélia Périssé Piquet • Centro de Pesquisa Candido Mendes - UCM

Sergio Ferraz Magalhães • Faculdade de Arquitetura e Urbanismo - UFRJ

Silvia Ramos • Centro de Estudos de Segurança e Cidadania - UCM

\section{REVISTA CADERNOS DO DESENVOLVIMENTO FLUMINENSE}

\section{COORDENAÇÃO}

Bruno Filippo

SECRETARIA EXECUTIVA

Ariana Falcão

REVISÃo

De responsabilidade dos autores

PROJETO GRÁFICO E DIAGRAMAÇÃO

Cláudio Novaes

R. São Francisco Xavier, 524/SI. 1050, Bloco FS - Maracanã

Rio de Janeiro • RJ - CEP 20550-013 - Telefone: (21) 2334-7313

revistacadernos.ceperj@gmail.com | www.e-publicacoes.uerj.br/ojs/index.php/cdf 



\section{Editorial}

Os Editores tem a satisfação de apresentar o conteúdo do $16^{\circ}$ número da REVISTA CADERNOS DO DESENVOLVIMENTO FLUMINENSE, que reflete o compromisso com uma reflexão acadêmica multidisciplinar sistemática tanto sobre contexto sócio-econômico-territorial do estado do Rio de Janeiro (ERJ), como também sobre orientações e práticas relevantes no campo das políticas públicas, orientadas para os enfrentamentos de desafios colocados em função de transformações contemporâneas da sociedade fluminense em suas múltiplas dimensões. Seguindo essa tradição, o presente número contempla tanto artigos baseados em reflexões de natureza mais geral, como abordagens mais focalizadas, em termos tanto do objeto de reflexão como do campo associado das políticas públicas. Traz colaborações de várias instituições do ERJ e abordagens de distintos campos disciplinares.

Em primeiro lugar, cabe destacar artigos com foco mais amplo em termos do diagnóstico socioeconômico do Estado do Rio de Janeiro, seja através de abordagens que contemplam tanto a configuração geral da estrutura produtiva, seja através de análises territorialmente mais localizadas da dinâmica socioeconômica. O artigo “Especialização produtiva: reflexos sobre o desenvolvimento do estado do Rio de Janeiro", de Henrique Cavalieri e Lia Hasenclever, analisa a evolução da estrutura produtiva do Estado do Rio de Janeiro, em comparação com a nacional. Ressalta-se a concentração em segmentos associados ao petróleo e mostra-se que essa especialização produtiva não tem se constituído em uma via de desenvolvimento virtuoso para o estado, pois tende a perpetuar e reproduzir heterogeneidades estruturais, refletidas em tendências de baixo crescimento econômico e vulnerabilidade externa.

No campo de um diagnóstico socioeconômico territorialmente mais localizado, o artigo "Relação entre renda petrolífera e melhoria na qualidade de vida por municípios confrontantes da Bacia de Campos", de Roberto Meireles Acruche, Ítalo de Oliveira Matias, Milton Erthal Jr, Fabio Freitas da Silva e Aldo Shimoya, tem como foco os nove municípios fluminenses pertencentes à Bacia de Campos. Por meio de uma pesquisa que usa o método de análise multicritério e dados do Índice FIRJAN (Federação das Indústrias do Rio de Janeiro) de Desenvolvimento Municipal, classifica os municípios e compara esta ordenação ao montante de rendas petrolíferas recebidas. Aponta-se que maiores níveis de royalties per capita não estão associados a melhores condições de desenvolvimento humano e constata-se uma dependência financeira dos municípios em relação à transferência e royalties acima de $70 \%$, com exceção da cidade de Macaé por concentrar a atividade petrolífera na região, sugerindo-se que a abundância de recursos naturais levou tanto a um afrouxamento fiscal e a uma tendência a negligenciar políticas públicas que estimulassem o desenvolvimento local.

Em sequência, o artigo "Desafios à gestão, ao desenvolvimento sustentável em Miracema (RJ)", de Paulo José de Mendonça Ribeiro, discute os impactos da criação de UC - Unidade de Conservação (UC) no município de Miracema, em 2010 como estratégia para promoção de um município "saudável e sustentável". Foi feita uma pesquisa de campo sobre: problemas de saneamento básico (lixo, esgoto, água e drenagem) e ambientais (erosão, desmatamento, contaminação da água), de modo a verificar em que medida a problemática socioambiental incorpora as questões relativas a qualidade de vida e bem-estar dos indivíduos e coletividades. As evidências coletadas sugerem que há mais custos que benefícios, particularmente no que se refere à sustentabilidade socioambiental, que representa um grande desafio para as políticas públicas.

O artigo "Inovação e Desenvolvimento Regional: uma análise sobre a produção científica da Universidade Estadual do Norte Fluminense e sua potencial contribuição para a sociedade", de Raquel Chaffin Cezario, Edson Terra Azevedo Filho e Henrique Rego Monteiro da Hora, pro- 
cura discutir, com base na experiência da Universidade Estadual do Norte Fluminense Darcy Ribeiro - UENF, o papel da universidade na sociedade, por meio da produção de conhecimento e da capacidade de induzir o desenvolvimento regional via inovação. A metodologia contempla uma abordagem quali-quantitativa mediante pesquisa bibliométrica no Banco de Dados Scopus. Constatou-se que a UENF tem gerado conhecimento relevante, por meio de publicações de documentos, principalmente na área das Ciências Agrárias e Biológicas, apresentando um potencial inovador capaz de contribuir com o desenvolvimento da Região desde que haja engajamento entre ela, governo e empresa, numa Hélice Tríplice.

Considerando um foco mais microscópico na abordagem da problemática do desenvolvimento socioeconômico local, o artigo "Perfil socioeconômico de feirantes do mercado municipal de Campos dos Goytacazes" de Graciela Aparecida Profeta, Raquel Chaffin Cezario, Elen Cristina de Mattos Lima e Vanuza da Silva Pereira Ney, procura caracterizar o perfil socioeconômico de feirantes de hortifrutícolas do mercado municipal de Campos dos Goytacazes, considerando aspectos relacionados aos canais de comercialização e as características econômicas que diferenciam os feirantes. Os resultados obtidos apontam que a renda mensal oriunda da feira era de extrema importância na composição da renda total da família, e, portanto, na sobrevivência das mesmas. Constatou-se também que os feirantes não usavam os circuitos curtos de produção que garantiriam a comercialização da produção local e que isso, além de não lhes fornecer produtos diferenciados para a venda, ainda implicava em perda de receita, pois acabavam competindo em condições desiguais com os supermercados da cidade.

$\mathrm{Na}$ transição entre abordagens de cunho mais analítico e abordagens com foco mais direcionado para a avaliação de políticas, o artigo "Casa popular própria: ilusão ou solução?", de Bianca Siqueira Gonçalves, Livia Maria de Souza Almeida Coura e José Luis Vianna da Cruz, é de natureza essencialmente conceitual, procurando discutir aspectos capazes de nortear a implementação de políticas habitacionais e urbanas, conectando a discussão do sonho de consumo da propriedade de um lugar para morar com as possibilidades de efetivação do direito à cidade, através de um revisão não sistemática da bibliografia sobre a origem da casa como mercadoria e objeto de desejo do trabalhador e sobre a questão da segregação sócio espacial à luz do Direito à Cidade. Ao mesmo tempo, procura-se articular essa discussão a aspectos importantes da estrutura e dinâmica da cidade, ressaltando-se o papel do planejamento urbano no sentido de mitigar a segregação socioespacial.

No campo mais operacional da avaliação de políticas, o artigo "Capilaridade territorial na provisão de medicamentos básicos no estado do Rio de Janeiro", de Eduardo Manhães e Lia Hasenclever, analisa a Política Pública de Assistência Farmacêutica (AF) nas mesorregiões do estado do Rio de Janeiro por meio da distribuição territorial das Unidades Básicas de Saúde (UBS) e dos estabelecimentos do Programa Farmácia Popular do Brasil. Aborda ainda a relação existente entre a instalação de unidades de AF com o volume populacional e a renda média per capita das mesorregiões no ano de 2018. A partir da construção de indicadores e da análise da correlação entre as variáveis, constata-se que, apesar de ter havido uma expansão da provisão de medicamentos, os estabelecimentos da rede credenciada são mais concentrados e os das UBS são mais dispersos no território, o que indica um melhor desempenho destas últimas em termos de distribuição territorial.

Ainda no campo da operacionalização de políticas públicas, o artigo "NudgeRio: um caso de aplicação de Ciência Comportamental às Políticas Públicas", de Otávio Morato de Andrade, discute possíveis soluções para políticas públicas baseadas em insights e fundamentos teóricos da Economia Comportamental, mais conhecidos como Nudges, termo que sugere a associação de incentivos comportamentais para reverter falhas cognitivas e que podem inspirar a criação de novas estratégias de aderência às políticas públicas. Especificamente, procura-se discutir com exemplos práticos de aplicações de Nudges no âmbito da governança estatal, em especial, o caso da NudgeRio, unidade criada na Prefeitura da Cidade do Rio. Refere-se ao caso da implementação do Programa Líderes Cariocas (PLC), coordenado pelo Instituto Fundação João Goulart (IFJG), que procura selecionar servidores públicos com perfil de liderança positiva e capacitá-los para assumir posições proeminentes na administração pública municipal. 
Por fim, no campo mais amplo da representação política, mas ainda com claros desdobramentos na definição de políticas públicas, o artigo "Mulher, política e cidade: reflexões analíticas", de Aimée Seixas de Sousa e María Gabriela Scotto, discute as relações entre mulheres, cidade, feminismo e participação em espaços de representação política. O caso da pesquisa em foco é a presença feminina na Câmara Municipal do Rio de Janeiro. Especificamente, a partir da implementação das cotas eleitorais para mulheres, busca-se discutir as relações entre a participação política e o direito à cidade sob a concepção de gênero. Argumenta-se que, numa perspectiva feminista, é possível pensar a mulher presente e atuante na política municipal como planejadora do espaço urbano e da vida das cidades, avaliando de maneira mais clara suas pretensões, interesses e demandas, apontando-se a necessidade de autonomia feminina no que diz respeito aos seus direitos como cidadãs e às escolhas sobre o acesso e a função do espaço público.

O conjunto de artigos presentes nesse número da REVISTA CADERNOS DO DESENVOLVIMENTO FLUMINENSE reflete o caráter multidisciplinar da discussão sobre o desenvolvimento fluminense e o compromisso em relação à avaliação de políticas públicas que norteiam a nossa linha editorial. Além disso, destacamos o compromisso do Conselho Editorial e das instituições de apoio no sentido de dar maior celeridade à avaliação das submissões e à atualização do processo de edição. É com base nessa perspectiva que reiteramos o convite à comunidade acadêmica para novas submissões que enriqueçam ainda mais a Revista. 



\title{
Especialização produtiva - reflexos sobre o desenvolvimento do estado do Rio de Janeiro
}

\section{Productive specialization: reflections on the development of the} state of Rio de Janeiro

\author{
Henrique Cavalieri ${ }^{1}$ (IE/UFRJ) \\ Lia Hasenclever² (UCAM e IE/UFRJ)
}

\begin{abstract}
RESUMO
O objetivo deste artigo é avaliar de que maneira a problemática do subdesenvolvimento, sugerida principalmente pela Comissão Econômica para a América Latina e o Caribe (Cepal) nos anos 1950, apresenta-se contemporaneamente ao estado do Rio de Janeiro (ERJ), tendo em vista o movimento recente de a economia estadual concentrar sua estrutura produtiva em segmentos associados ao petróleo. Para tanto, lança-se mão de dados sobre a estrutura produtiva do ERJ em comparação com a nacional, caracterizando a composição setorial e o padrão de desenvolvimento recente em níveis estadual e nacional. As principais conclusões do trabalho são que a especialização produtiva fluminense na indústria extrativa do petróleo não tem se constituído em uma via de desenvolvimento virtuoso para o estado. Ao contrário, o padrão de desenvolvimento atual tem perpetuado e reproduzido heterogeneidades estruturais, baixo crescimento econômico e vulnerabilidade externa.
\end{abstract}

PALAVRA-CHAVE: estrutura produtiva; intensidade tecnológica; indústria do petróleo; recursos naturais.

\section{ABSTRACT}

The objective of this article is to evaluate how the underdevelopment problem, mainly suggested by the Economic Commission for Latin America and the Caribbean (ECLAC) in the 1950s, arises contemporaneously within the state of Rio de Janeiro (RJ), in view of the recent move of the state economy towards segments associated with oil industry. The methodology is a comparative one and we use data on the production structure of $R J$ in comparison with the national, characterizing a sectorial composition and the pattern of recent development at state and national levels. The main conclusions are that the Rio productive specialization in the oil industry has not been constituted in a development path for the state. Instead, the current standard of growth has perpetuated and reproduced structural heterogeneity, low economic growth and external vulnerability.

KEYWORDS: productive structure; technological intensity; oil industry; natural resources.

\section{Introdução}

A literatura teórica sobre padrões de especialização produtiva e crescimento de longo prazo, mais especificamente aquela que concebe o setor industrial como um setor diferenciado e detentor de características que o tornam essencial para a diversificação das atividades produtivas e para o desenvolvimento econômico, é bastante vasta e antiga. De fato, as discussões originais sobre esse tema podem ser encontradas em autores ligados às teorias do desenvolvimento, como Hirschman (1958), Kaldor (1966) e autores da Comissão Econômica para a América Latina e o Caribe (Cepal) (BIELSCHOWSKY, 2000), que destacam características setoriais em nível macro, bem como em autores associados aos estudos de 
economia industrial, que identificam, ao nível da firma (micro), impulsos inerentes às empresas industriais a crescerem por meio da diversificação de suas atividades, como em Penrose (1959) e Chandler (1990).

Não obstante o fato de essa ser já uma literatura antiga, ela tem sido recorrentemente revisitada e renovada, haja vista as transformações econômicas mundiais que têm se apresentado e seus impactos diferenciados sobre o desenvolvimento econômico dos países.

A literatura empírica recente sobre essa temática questiona em que medida a exploração de recursos naturais apresenta-se atualmente como uma oportunidade de desenvolvimento aos países ricos nesses recursos, tendo em vista não apenas o contexto recente (e já arrefecido) de forte demanda internacional e aumento de preços desses bens, mas também a necessidade e oportunidade de avanços tecnológicos e científicos que a exploração de alguns desses recursos tem exigido, sugerindo uma reinterpretação das críticas elaboradas à especialização produtiva pelos "pioneiros do desenvolvimento" nas décadas 1950 e 1960 (GYLFASON, 2004; PEREZ, 2010).

O Brasil encontra-se no cerne dessa discussão, como atesta a proliferação recente de publicações sobre a possível desindustrialização do país e as consequências da reprimarização de sua pauta exportadora. Quando o foco é regional, a questão da especialização produtiva em bens primários se destaca principalmente no estado do Rio de Janeiro (ERJ), tendo em vista que o estado concentra $78 \%$ da produção nacional de petróleo e $64 \%$ da produção nacional de gás natural (ANP, 2020). Em relação à pauta de exportações fluminense, a título de ilustração, o produto óleo bruto de petróleo aumentou sua participação, entre 2000 e 2011, de 8,6\%, para $68 \%$, fazendo com que o ERJ se tornasse o terceiro maior estado exportador do país naquele ano, enquanto era apenas o nono no ano 2000 (PEREIRA, 2012).

Diante desse contexto, o objetivo deste artigo é avaliar como a problemática do subdesenvolvimento, sugerida principalmente pela Cepal nos anos 1950, apresenta-se contemporaneamente ao ERJ, a partir das mudanças recentes da estrutura produtiva estadual vis-à-vis a estrutura nacional. As perguntas de pesquisa são: (i) a estrutura produtiva e o recente padrão de desenvolvimento do ERJ, onde foram descobertas as maiores reservas de petróleo do país, são diferentes da estrutura e do padrão de desenvolvimento atual do Brasil? (ii) a indústria do petróleo e seus encadeamentos produtivos têm se mostrado como uma via de desenvolvimento sustentável para o ERJ?

Na concepção cepalina, o subdesenvolvimento é entendido como um processo particular experimentado por países periféricos, não se constituindo em uma etapa que necessariamente leva ao desenvolvimento econômico. Como característica principal do subdesenvolvimento, destaca-se a coexistência, em determinada sociedade, de um segmento industrial capitalista altamente produtivo e uma ampla faixa de economia de subsistência, com baixa produtividade e reduzida incorporação de progresso técnico. Assim, a despeito desse segmento industrial capitalista poder apresentar uma estrutura de custos e preços semelhante à dos países desenvolvidos e não obstante o fato de a parcela empregada nesse segmento ter salários elevados e proporcionar um aumento da renda per capita do conjunto da população, a maior parte da população ficaria alheia aos benefícios do desenvolvimento (FURTADO, 1967).

Nessa concepção, a partir de traços estruturais, como a heterogeneidade econômica, a baixa produtividade agregada, os salários reduzidos fora do segmento industrial capitalista e a instabilidade dos preços dos produtos primários, são geradas implicações negativas que se recolocam ao longo do tempo, como a reprodução da condição periférica e a deterioração dos termos de troca (COLISTETE, 2001). Portanto, a superação dessa condição passa pela diversificação da estrutura produtiva do país por meio de políticas industriais e tecnológicas que visem a mudanças estruturais profundas. É com esse referencial conceitual que este artigo analisa a especialização produtiva do ERJ, que parece estar adotando um caminho inverso ao preconizado para o alcance do desenvolvimento.

O artigo está organizado em mais quatro seções, além desta introdução. Na segunda seção é apresentada a metodologia, as fontes de dados e o modelo analítico utilizados. Na terceira seção apresenta-se a comparação entre as evoluções das estruturas produtivas fluminense e brasileira com destaque para a sua intensidade tecnológica e o seu grau de especialização. Na quarta seção, com base nos resultados da seção anterior, o padrão de desenvolvimento de cada uma das economias é classificado com base no tipo de mudança estrutural observado, apontando-se as particularidades de cada uma. A quinta seção conclui o trabalho. 


\section{Metodologia}

O estudo da estrutura produtiva fluminense em comparação com a estrutura nacional será feito a partir da classificação por intensidade tecnológica desenvolvida pela Organização para a Cooperação e Desenvolvimento Econômico (OCDE, 2011), bem como pela classificação por categorias de uso do Instituto Brasileiro de Geografia e Estatística (IBGE, 2013), que divide os segmentos das indústrias extrativa e de transformação em cinco categorias - bens intermediários, bens de consumo semidurável, bens de consumo não durável, bens de consumo durável e bens de capital. Para tanto, serão utilizados os dados da Pesquisa Industrial Anual - Empresa (PIA-Empresa do IBGE), por unidade local, desagregados a três dígitos (ou seja, ao nível de grupos), contemplando informações da indústria extrativa e da indústria de transformação desde 1996 até 2013.

A análise da estrutura produtiva terá como foco principal o valor da transformação industrial (VTI) dos diferentes setores. A variável VTI é vista e usualmente utilizada como uma proxy do valor agregado pela unidade local industrial. Os dados de cada segmento industrial serão deflacionados pelo seu respectivo Índice de Preços por Atacado da Fundação Getúlio Vargas (IPA-OG FGV), tendo-se como referência os preços de 2014.

A classificação da OCDE (2011) separa os setores industriais em quatro grupos distintos de intensidade tecnológica: alta (AT), média-alta (MAT), média-baixa (MBT) e baixa (BT) (OCDE, 2011). O Quadro 1 mostra os setores por intensidade tecnológica e seus respectivos códigos de Classificação Nacional de Atividades Econômicas versão 1.0 (CNAE 1.0). Os setores são ordenados de forma decrescente em relação à intensidade tecnológica, de maneira que mesmo dentro dos grupos tecnológicos há um ordenamento entre aqueles que são relativamente mais e menos intensivos. Como essa classificação trata apenas dos setores da indústria de transformação, a indústria extrativa será apresentada à parte, sem ser enquadrada em uma categoria tecnológica específica.

\begin{tabular}{|c|c|}
\hline Setores & CNAE 1.0 \\
\hline \multicolumn{2}{|l|}{ INDÚSTRIA DE ALTA TECNOLOGIA (AT) } \\
\hline Aeronáutica e aeroespacial & 35.3 \\
\hline Farmacêutica & 24.5 \\
\hline Material de escritório e informática & 30 \\
\hline Equipamentos de rádio, TV e comunicação & 32 \\
\hline Instrumentos médicos de ótica e precisão & 33 \\
\hline \multicolumn{2}{|l|}{ INDÚSTRIA DE MÉDIA-ALTA TECNOLOGIA (MAT) } \\
\hline Máquinas e equipamentos elétricos n. e. & 31 \\
\hline Veículos automotores, reboques e semi-reboques & 34 \\
\hline Produtos químicos, excl. farmacêuticos & 24 excl. 24.5 \\
\hline Equipamentos para ferrovia e material de transporte n. e. & $35.2+35.9$ \\
\hline Máquinas e equipamentos mecânicos n. e. & 29 \\
\hline \multicolumn{2}{|l|}{ INDÚSTRIA DE MÉDIA-BAIXA TECNOLOGIA (MBT) } \\
\hline Construção e reparação naval & 35.1 \\
\hline Borracha e produtos plásticos & 25 \\
\hline Produtos de petróleo refinado e outros combustíveis & 23 \\
\hline Outros produtos minerais não-metálicos & 26 \\
\hline Produtos metálicos & $27+28$ \\
\hline \multicolumn{2}{|l|}{ INDÚSTRIA DE BAIXA TECNOLOGIA (BT) } \\
\hline Produtos manufaturados n.e. e bens reciclados & $36+37$ \\
\hline Madeira e seus produtos, papel e celulose & $20+21+22$ \\
\hline Alimentos, bebidas e tabaco & $15+16$ \\
\hline Têxteis, couro e calçados & $17+18+19$ \\
\hline
\end{tabular}


A comparação entre a estrutura produtiva do ERJ e do Brasil será feita principalmente a partir da concentração relativa de cada categoria tecnológica e de uso na indústria estadual em comparação com a nacional. Para tanto, será calculado um indicador análogo ao indicador de vantagens comparativas reveladas de Balassa (1965). Esse indicador é calculado a partir do quociente entre a participação relativa de cada categoria tecnológica e de uso no VTI do ERJ e o seu par em nível nacional. O cálculo do indicador pode resultar em valores iguais, maiores ou menores que 1. Para valores iguais a 1, a participação relativa de determinada categoria tecnológica ou de uso na indústria fluminense é igual à participação observada na economia nacional; para valores acima de 1, a concentração é mais elevada em nível regional; para valores menores que 1, a concentração é relativamente menor no estado.

A caracterização do padrão de desenvolvimento do ERJ em contraponto ao padrão nacional será feita com base nas variáveis apontadas por Cepal (2012) como chave para se avaliar determinada mudança estrutural. Essas variáveis permitem caracterizar os padrões de desenvolvimento do Brasil e do ERJ e, principalmente, captar as principais diferenças entre eles, avaliando a qualidade da mudança estrutural, ou seja, se há ou não uma eficiência dinâmica que levaria ao desenvolvimento sustentável.

De fato, segundo o referido documento, pode haver diferentes padrões de desenvolvimento associados ao tipo ou intensidade de mudança estrutural em curso em uma determinada economia. Como indicado no Quadro 2 a seguir, um processo de expansão "virtuoso" indica uma mudança estrutural forte, em que produtividade e emprego crescem simultaneamente, combinando elevado crescimento da demanda agregada e maior participação de setores mais produtivos. Essa mudança proporciona o surgimento de novas atividades com maior produtividade e que absorvem empregos mais bem remunerados, reduzindo as desigualdades de renda internas ao país, bem como a brecha externa de produtividade em relação aos demais países. Tais atividades estão geralmente associadas a segmentos industriais e de serviços intensivos em conhecimento. No caso de uma mudança estrutural nula, a economia fica presa em um "círculo vicioso", no qual baixo crescimento da demanda agregada e estagnação da produtividade se retroalimentam. Os casos intermediários são os de mudança estrutural limitada a enclaves, que caracteriza um padrão de desenvolvimento do tipo "ajuste defensivo", pois combina baixos patamares de demanda agregada com a modernização e expansão da produtividade de apenas algumas atividades, e, por fim, mudança estrutural débil, em que, apesar de haver a expansão da demanda agregada (muitas vezes externa), há uma estagnação da produtividade, indicando um padrão de desenvolvimento do tipo "absorção de emprego" (CEPAL, 2012).

\begin{tabular}{|c|c|c|c|}
\hline \multirow{2}{*}{\multicolumn{2}{|c|}{ Crescimento do emprego }} & \multicolumn{2}{|c|}{ Crescimento da produtividade } \\
\hline & & \multirow{2}{*}{$\begin{array}{c}\text { BAIXO } \\
\text { Absorção de emprego }\end{array}$} & \multirow{2}{*}{$\begin{array}{c}\text { ALTO } \\
\text { Círculo virtuoso }\end{array}$} \\
\hline \multirow{4}{*}{ ELEVADO } & Tipo de padrão & & \\
\hline & Macroeconomia & $\begin{array}{l}\text { Forte crescimento da } \\
\text { demanda agregada }\end{array}$ & $\begin{array}{l}\text { Forte crescimento da } \\
\text { demanda agregada }\end{array}$ \\
\hline & Progresso técnico e inovação & $\begin{array}{l}\text { Baixo ou nulo } \\
\text { crescimento da } \\
\text { produtividade }\end{array}$ & $\begin{array}{c}\text { Forte crescimento da } \\
\text { produtividade }\end{array}$ \\
\hline & Tipo de mudança estrutural & $\begin{array}{l}\text { Débil mudança } \\
\text { estrutural }\end{array}$ & $\begin{array}{l}\text { Forte mudança } \\
\text { estrutural }\end{array}$ \\
\hline \multirow{4}{*}{ BAIXO } & Tipo de padrão & Círculo vicioso & Ajuste defensivo \\
\hline & Macroeconomia & $\begin{array}{c}\text { Baixo ou nulo } \\
\text { crescimento da } \\
\text { demanda agregada }\end{array}$ & $\begin{array}{l}\text { Baixo crescimento da } \\
\text { demanda agregada }\end{array}$ \\
\hline & Progresso técnico e inovação & $\begin{array}{l}\text { Baixo ou nulo } \\
\text { crescimento da } \\
\text { produtividade }\end{array}$ & $\begin{array}{c}\text { Forte crescimento da } \\
\text { produtividade }\end{array}$ \\
\hline & Tipo de mudança estrutural & $\begin{array}{l}\text { Nula mudança } \\
\text { estrutural }\end{array}$ & $\begin{array}{l}\text { Mudança estrutural } \\
\text { limitada a enclaves }\end{array}$ \\
\hline
\end{tabular}




\section{Estrutura produtiva: Rio de Janeiro versus Brasil}

A Tabela 1 apresenta o VTI da indústria de transformação do ERJ por intensidade tecnológica e o VTI da indústria extrativa, com destaque para petróleo e gás. O Gráfico 1, por sua vez, ilustra as participações de cada uma das categorias tecnológicas e da indústria extrativa na geração do VTI fluminense. De maneira geral, os dados mostram que a estrutura produtiva do estado era, na segunda metade dos anos 1990, predominantemente composta por segmentos de MBT, BT e atividade extrativa de P\&G. Essas três categorias abarcavam, em média, quase $80 \%$ do VTI fluminense entre 1996 e 2000, sendo o restante distribuído em 13\% para as atividades de MAT, e 7\% para AT.

Ao longo dos anos 2000, porém, essa estrutura passou por algumas transformações importantes. De fato, o maior destaque positivo ficou por conta do desempenho da indústria extrativa de P\&G, que alcançou uma taxa média de crescimento anual de $8 \%$ no período como um todo (1996-2013), passando a abarcar, em 2013, 37\% do VTI fluminense, o equivalente a R\$ 43,5 bilhões. O segundo lugar em termos de avanço ficou com as atividades de MAT, que saíram de um VTI médio de R\$ 8,76 bilhões na segunda metade dos anos 1990, para $\mathrm{R} \$ 20,48$ bilhões em 2013, o equivalente a uma taxa média de crescimento anual de $5 \%$, representando, no último ano da série, $17 \%$ do VTI do estado.

TABELA 1: VTI por intensidade tecnológica no ERJ (bilhões R\$̣ de 2014), 1996-2013

\begin{tabular}{|c|c|c|c|c|c|c|c|c|c|}
\hline $\begin{array}{l}\text { Intensidade } \\
\text { tecnológica }\end{array}$ & $\begin{array}{c}\text { Média } \\
96-00\end{array}$ & 2003 & 2005 & 2007 & 2009 & 2011 & 2013 & $\begin{array}{c}\text { Var. } \\
\text { média } \\
\text { anual }\end{array}$ & $\begin{array}{c}\text { Var. } \\
96-13\end{array}$ \\
\hline AT & 5,17 & 4,15 & 3,96 & 3,47 & 4,25 & 3,20 & 3,29 & $-3 \%$ & $-40 \%$ \\
\hline MAT & 8,76 & 8,74 & 9,17 & 11,37 & 12,91 & 16,72 & 20,48 & $5 \%$ & $148 \%$ \\
\hline MBT & 24,65 & 35,23 & 33,02 & 34,74 & 30,48 & 44,60 & 37,63 & $2 \%$ & $38 \%$ \\
\hline BT & 14,71 & 10,44 & 11,24 & 9,41 & 11,52 & 12,81 & 12,41 & $-1 \%$ & $-20 \%$ \\
\hline $\begin{array}{c}\text { Extrativa } \\
\text { (exceto } P \& G \text { ) }\end{array}$ & 1,08 & 0,39 & 0,33 & 0,39 & 0,37 & 0,67 & 0,67 & $-4 \%$ & $-51 \%$ \\
\hline Petróleo e Gás & 14,60 & 28,44 & 30,10 & 31,37 & 36,83 & 42,62 & 43,49 & $8 \%$ & $281 \%$ \\
\hline Total & 68,97 & 87,39 & 87,81 & 90,74 & 96,37 & 120,63 & 117,97 & $3 \%$ & $70 \%$ \\
\hline
\end{tabular}

Fonte: Elaboração própria a partir da PIA-Empresa, IBGE.

Nota: Dados atualizados pelo IPA-OG (FGV). Classificação por intensidade tecnológica de acordo com OCDE (2011).

GRÁFICO 1: Participação (\%) do VTI por categoria tecnológica no ERJ, 1996-2013

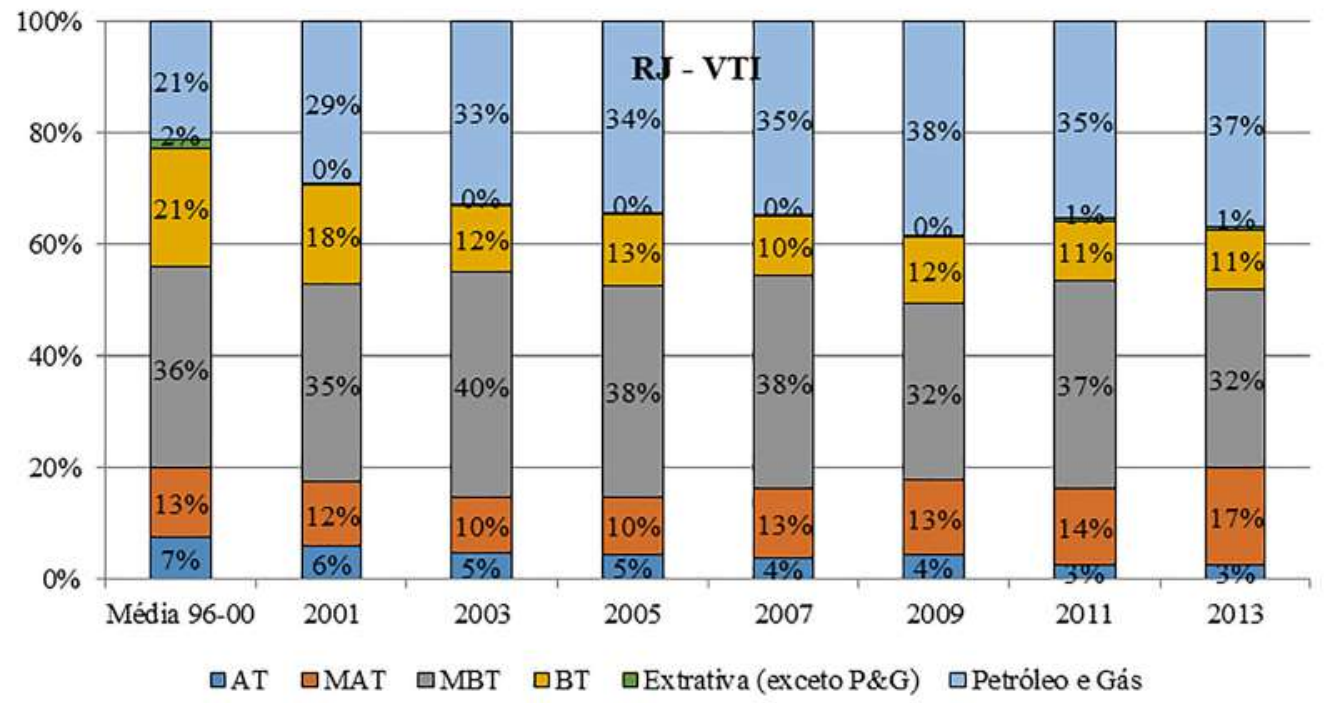

Fonte: Elaboração própria a partir da PIA-Empresa, IBGE.

Nota: Dados atualizados pelo IPA-OG (FGV). Classificação por intensidade tecnológica de acordo com OCDE (2011). 
As demais categorias que eram destaque na segunda metade dos anos 1990 perderam representatividade. Os segmentos de MBT expandiram seu VTI a um ritmo menor que a média da economia fluminense ( $2 \%$ contra $3 \%$ ao ano), recuando, assim, sua participação de $36 \%$, na média do período 19962000, para 32\%, em 2013. Já as atividades de BT tiveram um recuo em termos absolutos na geração de VTI, representando uma perda de dez pontos percentuais de participação no VTI do estado no período analisado, ainda que tenham tido alguma reação a partir de 2007. O pior desempenho, porém, ficou por conta justamente dos segmentos mais intensivos em tecnologia, que apresentaram retrações em termos absolutos de VTI de forma persistente ao longo dos anos 2000. Assim, a categoria AT, que apresentou uma taxa média de crescimento negativa em $3 \%$, reduziu sua participação no VTI estadual de $7 \%$ para $3 \%$ no período analisado.

Analisando-se mais detidamente os segmentos que compõem cada uma das categorias tecnológicas, constata-se que os principais responsáveis pelo tom geral dos movimentos descritos foram poucos setores. Na categoria de MAT, os principais responsáveis pelo crescimento foram a indústria química (exclusive farmacêutica) e a indústria de fabricação e montagem de veículos automotores, reboques e carrocerias. A indústria química apresentou expressivo crescimento a partir do ano 2008, mantendo-se como o principal segmento da categoria $\mathrm{MAT}^{3}$. Já a indústria automotiva demonstrou uma trajetória de forte crescimento já a partir de 1997, com expressivos saltos positivos nos anos de 1998, 2008, 2010 e 2011, figurando como o segundo setor mais importante dessa categoria tecnológica. Nos segmentos automotivos, o maior destaque foi a fabricação de caminhões e ônibus, com forte crescimento em todo o período analisado, sendo seguido pelo ramo de fabricação de automóveis, caminhonetas e utilitários, que entrou numa trajetória de amplo crescimento a partir do ano 2000, mas demonstrou retrações após 2008.

Para ilustrar essa expansão da indústria automotiva no ERJ, pode-se citar o fato de que, em 1996, havia oito unidades locais industriais do ramo de automóveis, caminhonetas e utilitários, e apenas duas instaladas no ERJ pertencentes aos segmentos de caminhões e ônibus; em 2013, esses números eram de dez e cinco unidades, respectivamente. No período, a região sul do ERJ, com destaque para os municípios de Resende, Itatiaia e Porto Real, tornou-se um polo da indústria automobilística, abrigando montadoras como a MAN-Volkswagen, Peugeot-Citroen, Hyundai e Nissan, não obstante essa região e o estado ainda apresentem números modestos em comparação com o polo de São Paulo (SANTOS, 2011).

Na categoria de MBT, o principal segmento no período analisado foi o de fabricação de produtos derivados do petróleo, seguido pela atividade de metalurgia básica. A fabricação de derivados do petróleo, que representou, em geral, mais de $50 \%$ do VTI da categoria de MBT, apresentou um crescimento de $74 \%$ entre 1996 e 2013. Já a metalurgia básica, que detém cerca de $20 \%$ do VTI da indústria de MBT, manteve sua geração de VTI praticamente no mesmo patamar ao longo do período, com algumas oscilações.

Com relação à categoria de $\mathrm{BT}$, o principal segmento foi o de fabricação de alimentos e bebidas, que detém, em média, 50\% de participação no VTI da categoria. Tal indústria apresentou forte recuo até meados dos anos 2000, com alguma recuperação nos anos finais, mas sem voltar ao patamar existente no início do período analisado. Por fim, no que diz respeito à indústria de AT, o principal responsável por seu desempenho decepcionante foi a indústria farmacêutica, que encolheu no período analisado $51 \%$ em termos de VTI. Em 1996, esse segmento correspondia a 95\% da categoria AT no ERJ, sendo que, em 2013, tal participação havia recuado para 78\%.

A partir dos dados apresentados, depreende-se que o ERJ aumentou sua dependência econômica em segmentos associados ao petróleo, abrindo mão tanto de atividades tradicionais (como alimentos e bebidas), geralmente intensivas em mão de obra, como de atividades de ponta (como a indústria farmacêutica), reduzindo, assim, o escopo de diversificação de sua estrutura produtiva e seus potenciais de encadeamentos. Como agravante, essa dependência do petróleo é notoriamente associada às etapas extrativas da produção, ainda que a etapa de refino e a indústria química de forma geral também tenham apresentado crescimento no período analisado. Um movimento no sentido da diversificação

3 Pelas regras de desidentificação do IBGE, que visam assegurar o sigilo das informações individualizadas das empresas, fica impossibilitada a identificação do ramo químico específico responsável por maior parte do crescimento. 
parece ter sido dado com a indústria automotiva, atividade que reconhecidamente possui forte poder de encadeamentos produtivos e absorção de empregos diretos e indiretos.

A fim de averiguar até que ponto o desempenho descrito pelo ERJ acompanha um padrão nacional ou mesmo apresenta um modelo e trajetórias próprias, a Tabela 2 apresenta o cálculo do indicador de concentração relativa descrito na seção metodológica. Esse indicador compara a participação relativa de cada categoria tecnológica do ERJ com o seu par nacional.

De acordo com os dados da Tabela 2, pode-se concluir que, já na segunda metade da década de 1990, a estrutura produtiva do ERJ era significativamente concentrada na extração de petróleo e gás em comparação com a estrutura produtiva nacional, sendo essa concentração cerca de 7 vezes superior no estado fluminense. $O$ forte ritmo de expansão que essa atividade teve no ERJ ocorreu pari passu ao aumento da participação dessa atividade no VTI do país como um todo, de forma que o indicador não variou muito no período analisado. Assim, embora a concentração do VTI dessa atividade no ERJ seja de 6 a 7 vezes superior à concentração nacional, a participação dessa atividade em ambas as estruturas avançou a um ritmo semelhante.

TABELA 2: Concentrações Relativas por categorias tecnológicas - VTI ERJ/VTI BR

\begin{tabular}{|c|c|c|c|c|c|c|c|}
\hline $\begin{array}{l}\text { Intensidade } \\
\text { tecnológica }\end{array}$ & $\begin{array}{l}\text { Média } \\
96-00\end{array}$ & 2003 & 2005 & 2007 & 2009 & 2011 & 2013 \\
\hline AT & 1,5 & 1,2 & 1,0 & 0,8 & 0,9 & 0,6 & 0,5 \\
\hline MAT & 0,6 & 0,5 & 0,5 & 0,5 & 0,6 & 0,6 & 0,7 \\
\hline MBT & 1,1 & 1,2 & 1,2 & 1,2 & 1,2 & 1,4 & 1,2 \\
\hline BT & 0,6 & 0,4 & 0,4 & 0,3 & 0,4 & 0,3 & 0,3 \\
\hline Extrativa (exceto P\&G) & 0,3 & 0,1 & 0,1 & 0,1 & 0,1 & 0,1 & 0,1 \\
\hline Petróleo e Gás & 6,8 & 6,4 & 6,5 & 7,1 & 6,8 & 6,4 & 6,0 \\
\hline Total & 1,0 & 1,0 & 1,0 & 1,0 & 1,0 & 1,0 & 1,0 \\
\hline
\end{tabular}

Fonte: Elaboração própria a partir da PIA-Empresa, IBGE.

Nota: Dados atualizados pelo IPA-OG (FGV). Classificação por intensidade tecnológica de acordo com OCDE (2011).

Com relação ao segmento de MBT, constata-se que a alta participação dessa categoria tecnológica na geração do VTI fluminense é ligeiramente superior ao que se observa em nível nacional e, portanto, sabe-se que a estrutura produtiva brasileira também é fortemente baseada em bens de MBT. Apesar do recuo relativo que essa categoria descreveu no ERJ ao longo do período analisado, como indicado no Gráfico 1, o indicador de concentração relativa aumentou de 1,1 para 1,2, indicando que o movimento de perda relativa de participação dos segmentos MBT foi um fenômeno que aconteceu também em nível nacional e, ainda, de maneira mais intensa.

Por outro lado, a rápida expansão absoluta e relativa da categoria MAT no VTI do ERJ não foi suficiente para aproximar a estrutura estadual da estrutura nacional, que, além de apresentar uma proporção maior de seu VTI gerado por segmentos de MAT, apresentou uma expansão dessas atividades a um ritmo semelhante ao observado no ERJ. Nota-se, portanto, que a expansão vista em âmbito estadual não destoou da trajetória descrita em nível nacional, enfraquecendo uma possível hipótese de que os segmentos de MAT do país estivessem migrando de outras regiões para o ERJ.

Já as perdas absolutas e relativas das categorias BT e AT presenciadas para o ERJ não encontraram equivalentes em nível nacional. Se a categoria BT já era relativamente menos importante no ERJ do que na estrutura produtiva do Brasil na segunda metade dos anos 1990, nos anos 2000 essa proporção reduziu-se ainda mais, caindo de 0,6, no primeiro período, para 0,3, em 2013. Diferentemente do que ocorreu no ERJ, a categoria BT, no Brasil, apresentou avanços em termos absolutos e preservou sua participação no VTI do país entre $31 \%$ e $33 \%$ no período analisado.

Com relação à categoria de atividades de AT, nota-se que a perda de participação relativa no ERJ foi bastante dramática, fazendo o indicador cair de 1,5, na média do período 1996-2000, para 0,5, em 2013. 
Assim, enquanto na segunda metade dos anos 1990 o ERJ tinha uma estrutura produtiva relativamente concentrada em atividades altamente tecnológicas, tendo-se como parâmetro a estrutura produtiva nacional, esse perfil foi drasticamente sobrepujado nos anos 2000, de forma que a importância desses segmentos no VTI do estado passou a ser equivalente a apenas $50 \%$ da importância dessa indústria em âmbito nacional, que, diga-se de passagem, não apresenta uma estrutura produtiva altamente tecnológica. Diferentemente do que ocorreu no ERJ, a categoria AT, no Brasil, apresentou uma expansão absoluta, mantendo sua participação relativa em torno de $5 \%$ a $6 \%$ do VTI nacional. Nesse caso, pode-se sugerir que atividades de alta tecnologia antes localizadas no ERJ, com destaque para a indústria farmacêutica, foram deslocadas para outras unidades da federação.

Os dados da Tabela 3 sobre produtividade do trabalho são, em alguma medida, condizentes com aqueles da Tabela 2. Como se nota, as atividades de AT realizadas no ERJ eram, em 1996, significativamente mais produtivas que aquelas do agregado nacional. Ao longo do período analisado, porém, a produtividade recuou no ERJ e avançou no Brasil, de forma que, em 2013, o país havia superado o estado fluminense. Já as atividades de MAT apresentavam produtividades bastante semelhantes no ERJ e no Brasil no ano de 1996, em torno de R\$155 mil por pessoal ocupado. Em 2013, porém, a produtividade do trabalho no ERJ avançou para $\mathrm{R} \$ 223$ mil, enquanto a produtividade em nível nacional se manteve no patamar da década de 1990.

TABELA 3: Produtividade do trabalho, Brasil e ERJ (VTI/PO, R\$ 1.000 de 2014), 1996 e 2013

\begin{tabular}{|lcccc|}
\multirow{2}{*}{ Intensidade tecnológica } & \multicolumn{3}{c}{$\mathbf{2 0 1 3}$} \\
\cline { 2 - 5 } & Brasil & ERJ & Brasil & ERJ \\
\hline AT & 136,96 & 192,06 & 165,72 & 147,83 \\
\hline MAT & 154,62 & 154,91 & 152,17 & 221,53 \\
\hline MBT & 190,62 & 256,82 & 147,78 & 223,34 \\
\hline BT & 85,99 & 78,94 & 84,25 & 72,93 \\
\hline Extração petróleo e gás & 921,39 & $1.557,68$ & $1.168,98$ & $1.242,41$ \\
\hline Total & $\mathbf{1 3 1 , 0 0}$ & $\mathbf{1 7 4 , 0 6}$ & $\mathbf{1 2 9 , 0 9}$ & $\mathbf{2 3 7 , 0 8}$ \\
\hline
\end{tabular}

Fonte: Elaboração própria a partir da PIA-Empresa, IBGE.

Nota: Valores atualizados pela IPA-OG, preços de 2014. Classificação por intensidade tecnológica baseada em OCDE (2011).

Com relação às atividades de $\mathrm{MBT}$ e de BT, constata-se, na Tabela 3, a elevada produtividade no ERJ em comparação com o Brasil, no primeiro caso, e sua baixa produtividade, no segundo caso, tanto em 1996 como em 2013. Tal fato é uma das características da conclusão obtida a partir da Tabela 2, qual seja, da vocação do ERJ para atividades de MBT, por um lado, e da menor importância relativa no estado dos segmentos de BT, sempre em comparação com a estrutura produtiva do Brasil.

Ainda na Tabela 3, chama atenção a elevada produtividade do segmento extrativo de P\&G quando comparado com demais categorias tecnológicas. Tal fato é natural que ocorra, tendo em vista a alta intensidade de capital que é característica desse setor. Ademais, cabe ressaltar que, já em 1996, o ERJ detinha uma produtividade muito mais elevada que a produtividade agregada da atividade em nível nacional e, portanto, forte vantagem no desenvolvimento dessa indústria. Ao longo do período analisado, contudo, nota-se uma convergência entre as regiões, de forma que, em 2013, o diferencial de produtividade a favor do ERJ, apesar de positivo, tornou-se muito menor que aquele de 1996.

Por fim, a produtividade agregada da indústria (extrativa e de transformação), indicada na linha referente ao total da Tabela 3, ficou, em nível nacional, estagnada em torno de R\$ 130 mil, enquanto, para o ERJ, além de iniciar a série em um patamar mais elevado, de R\$174 mil, alcançou um aumento de $36 \%$ entre 1996 e 2013. Apesar de, à primeira vista, ser este um fato favorável ao ERJ, sugere-se aqui que esse aumento da produtividade do trabalho agregada da indústria fluminense esteve diretamente relacionado ao aumento da participação do setor extrativo de petróleo e 
gás na estrutura produtiva do estado (de 21\%, 1996, para 36\% do VTI gerado em 2013, conforme Gráfico 1). Trata-se, portanto, principalmente de um efeito composição, resultado do aumento de participação de um setor intensivo em capital na indústria do ERJ, e não necessariamente de um aumento de eficiência da indústria fluminense. Esse fato fica ainda mais claro ao se constatar que apenas a categoria MAT apresentou uma expansão da produtividade do trabalho na comparação entre os anos de 1996 e 2013, sendo que todas as demais categorias tecnológicas demonstraram involuções.

Quando se agrega o VTI fluminense por categorias de uso do IBGE, constata-se que a indústria do ERJ é, essencialmente, produtora de bens intermediários, como se nota a partir dos dados das Tabelas 4 e 5 . Isso fica evidente ao se destacar que, nessa categoria de bens, estão os produtos oriundos da indústria extrativa de petróleo, do refino de petróleo e da indústria metalúrgica, segmentos que, como já destacado, possuem grande expressão no ERJ.

TABELA 4: VTI por categoria de uso no ERJ (bilhões R\$̣ de 2014), 1996-2013

\begin{tabular}{|lccccccc|cc|} 
Categorias de uso & $\begin{array}{c}\mathbf{1 9 9 6 -} \\
\mathbf{2 0 0 0}\end{array}$ & $\mathbf{2 0 0 3}$ & $\mathbf{2 0 0 5}$ & $\mathbf{2 0 0 7}$ & $\mathbf{2 0 0 9}$ & $\mathbf{2 0 1 1}$ & $\mathbf{2 0 1 3}$ & $\begin{array}{c}\text { Var. } \\
\text { média } \\
\text { anual }\end{array}$ & $\begin{array}{c}\text { Var. } \\
\mathbf{9 6 - 1 3}\end{array}$ \\
\hline Bens intermediários & $\mathbf{4 6 , 3 9}$ & $\mathbf{6 8 , 7 6}$ & $\mathbf{6 8 , 6 9}$ & $\mathbf{6 9 , 8 3}$ & $\mathbf{6 9 , 5 2}$ & $\mathbf{8 7 , 0 4}$ & $\mathbf{8 0 , 5 0}$ & $3 \%$ & $\mathbf{7 4 \%}$ \\
\hline Bens de capital & 2,52 & 4,49 & 4,20 & 3,38 & 4,03 & 6,95 & 7,42 & $9 \%$ & $330 \%$ \\
\hline Durável & $\mathbf{2 , 0 8}$ & $\mathbf{0 , 4 5}$ & $\mathbf{0 , 6 6}$ & 1,02 & 1,24 & 1,13 & 1,46 & $16 \%$ & $1.105 \%$ \\
\hline Semidurável & 1,90 & 1,33 & 1,39 & 1,57 & 2,32 & 2,62 & 3,17 & $3 \%$ & $65 \%$ \\
\hline Não durável & 17,24 & 11,90 & 12,13 & $\mathbf{9 , 6 7}$ & 11,21 & 11,78 & 11,25 & $-3 \%$ & $-39 \%$ \\
\hline Total & $\mathbf{6 8 , 1 2}$ & $\mathbf{8 6 , 9 3}$ & $\mathbf{8 7 , 0 7}$ & $\mathbf{8 5 , 4 8}$ & $\mathbf{8 8 , 3 2}$ & $\mathbf{1 0 9 , 5 3}$ & $\mathbf{1 0 3 , 8 0}$ & $\mathbf{2} \%$ & $\mathbf{5 2 \%}$ \\
\hline
\end{tabular}

Fonte: Elaboração própria a partir da PIA-Empresa, IBGE.

Nota: Dados atualizados pelo IPA-OG (FGV). Classificação por categorias de uso do IBGE.

TABELA 5: Participação relativa de cada categoria de uso no VTI do ERJ e índice de concentração relativa entre ERJ e Brasil, anos selecionados

\begin{tabular}{|c|c|c|c|c|c|c|}
\hline \multirow[t]{2}{*}{ Categorias de uso } & \multicolumn{3}{|c|}{ Participação VTI ERJ } & \multicolumn{3}{|c|}{$\begin{array}{l}\text { Participação VTI ERJ/ } \\
\text { Participação VTI Br }\end{array}$} \\
\hline & $1996-2000$ & 2007 & 2013 & $1996-2000$ & 2007 & 2013 \\
\hline Bens intermediários & $68 \%$ & $82 \%$ & $78 \%$ & 1,08 & 1,27 & 1,31 \\
\hline Bens de capital & $4 \%$ & $4 \%$ & $7 \%$ & 0,64 & 0,55 & 0,69 \\
\hline Durável & $0 \%$ & $1 \%$ & $1 \%$ & 0,03 & 0,27 & 0,29 \\
\hline Semidurável & $3 \%$ & $2 \%$ & $3 \%$ & 0,86 & 0,42 & 0,53 \\
\hline Não durável & $25 \%$ & $11 \%$ & $11 \%$ & 1,03 & 0,57 & 0,54 \\
\hline Total & $100 \%$ & $100 \%$ & $100 \%$ & 1,00 & 1,00 & 1,00 \\
\hline
\end{tabular}

Fonte: Elaboração própria a partir da PIA-Empresa, IBGE.

Nota: Dados atualizados pelo IPA-OG (FGV). Classificação por categorias de uso do IBGE.

De acordo com a Tabela 5, os bens intermediários representavam, na média do período 1996-2000, $68 \%$ do VTI fluminense. Expandindo-se a uma taxa média anual de $3 \%$ ao ano, enquanto o setor industrial como um todo cresceu a uma taxa de $2 \%$, os bens intermediários chegaram a $78 \%$ do VTI estadual em 2013. Comparando-se a relevância dessa categoria para o ERJ com seu par nacional, percebe-se que, já na segunda metade dos anos 1990, o estado era $8 \%$ mais concentrado em bens intermediários que o país. Em 2013, tal relação aumentou para 31\%, conforme dados da Tabela 5.

Em termos de expansão, porém, a categoria de maior destaque foi a de bens de consumo durável (crescimento médio de 16\% ao ano entre 1996 e 2013), seguida pelos bens de capital ( $9 \%$ ao ano). O forte crescimento dos bens de consumo durável foi resultado quase que exclusivamente da expansão do segmento produtor de automóveis, enquanto o avanço dos bens de capital foi liderado pelo segmento de fabricação de caminhões e ônibus, seguido pela construção de embarcações. 
As duas categorias, ainda que tenham apresentado grande expansão, abrangem pouco percentual relativo do VTI estadual, de acordo com a Tabela 5.

Uma perda relevante para o estado ficou por conta dos bens de consumo não durável, que apresentou uma retração em termos absolutos no período analisado. Essa retração foi resultado, principalmente, do desempenho da indústria farmacêutica e, até meados dos anos 2000 , da indústria de alimentos e bebidas, como já ressaltado anteriormente.

\section{Padrão de desenvolvimento: Rio de Janeiro versus Brasil}

Como indicado na seção anterior, o bom desempenho da indústria extrativa do petróleo, um segmento intensivo em capital e com elevada produtividade do trabalho, resultou em um aumento da produtividade agregada da indústria estadual bastante superior ao percebido pela indústria nacional, mesmo se tratando de uma atividade que se encontra no início da cadeia produtiva. De acordo com o Gráfico 2, nota-se que a produtividade do trabalho na indústria fluminense cresceu mais rapidamente que a produtividade na indústria nacional em todos os anos após 1998. De fato, enquanto a produtividade estadual havia crescido, em 2013, cerca de $30 \%$ em comparação com 1996, a produtividade da indústria nacional recuara, no mesmo período, 1,5\%.

GRÁFICO 2: Produtividade do trabalho (VTI/PO, 1996=100) na indústria brasileira e fluminense, 1996-2013

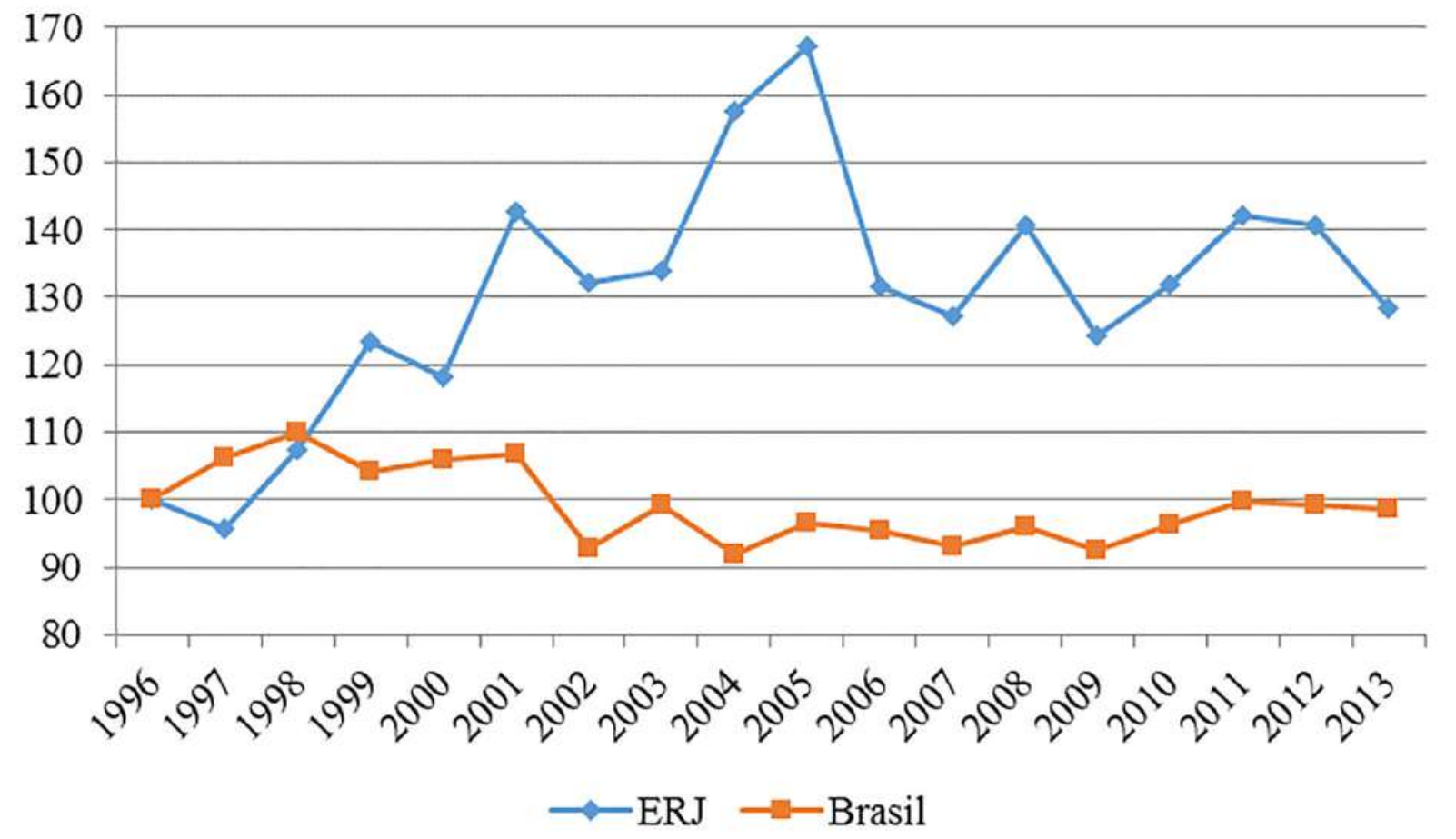

Fonte: Elaboração própria com base na PIA-Empresa/IBGE.

Nota: Dados atualizados pelo IPA-OG (FGV).

Porém, a forte expansão da produtividade agregada do ERJ foi resultado, como visto, não de um processo generalizado de crescimento da eficiência de vários setores, mas, sim, do efeito composição obtido a partir do aumento de participação de um setor extrativo intensivo em capital no tecido produtivo do estado. Com isso, tampouco se presenciou, no ERJ, um movimento no sentido da diversificação da estrutura produtiva típico de processos de desenvolvimento em que há uma retroalimentação positiva entre crescimento, produtividade e diversificação, mas, no sentido oposto, o que aconteceu foi um aumento da concentração da indústria fluminense. Ressalte-se que essa maior concentração aconteceu em um contexto em que a estrutura produtiva nacional caminhava na direção da diversificação. 
Nesse sentido, não surpreende o fato de o ERJ não ter alcançado um bom desempenho econômico no período recente. Como indicado no Gráfico 3, a expansão do PIB per capita fluminense ficou aquém do desempenho nacional em todos os anos de 1996 a 2013. No último ano da série, o PIB per capita do país como um todo era $33 \%$ superior àquele de 1996; em âmbito estadual, tal variação foi de apenas $25 \%$. De forma análoga, a geração do emprego no estado se deu a uma taxa inferior a taxa nacional em todo o período sob estudo.

GRÁFICO 3: PIB per capita, Brasil e ERJ (1996 = 100), 1996-2011

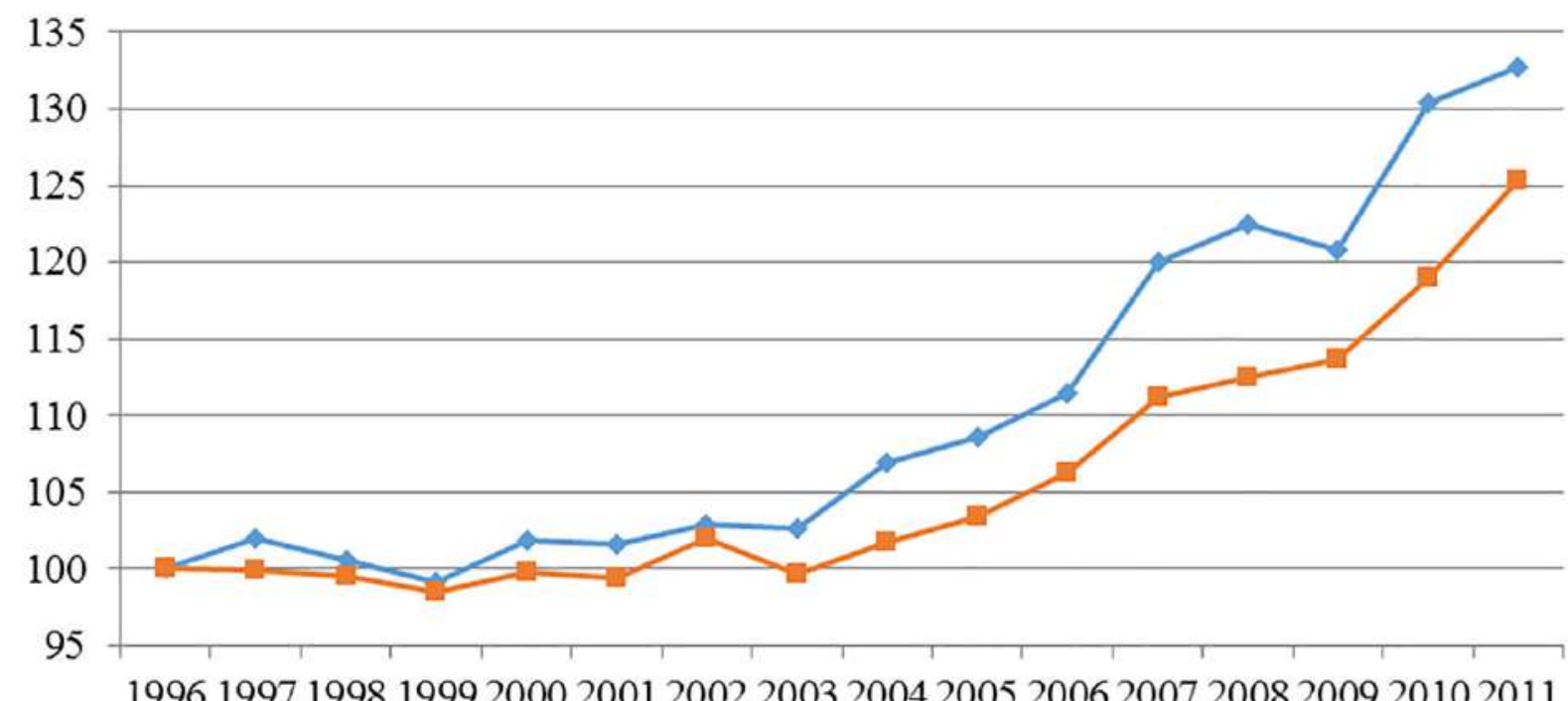

$\because$ PIB per capita BR $\quad \rightarrow$ PIB per capita ERJ

Fonte: Elaboração própria com base na PIA-Empresa/IBGE.

Nota: Dados atualizados pelo IPA-OG (FGV).

GRÁFICO 4: Evolução do emprego (PO) no Brasil e no ERJ (1996=100), 1996-2013

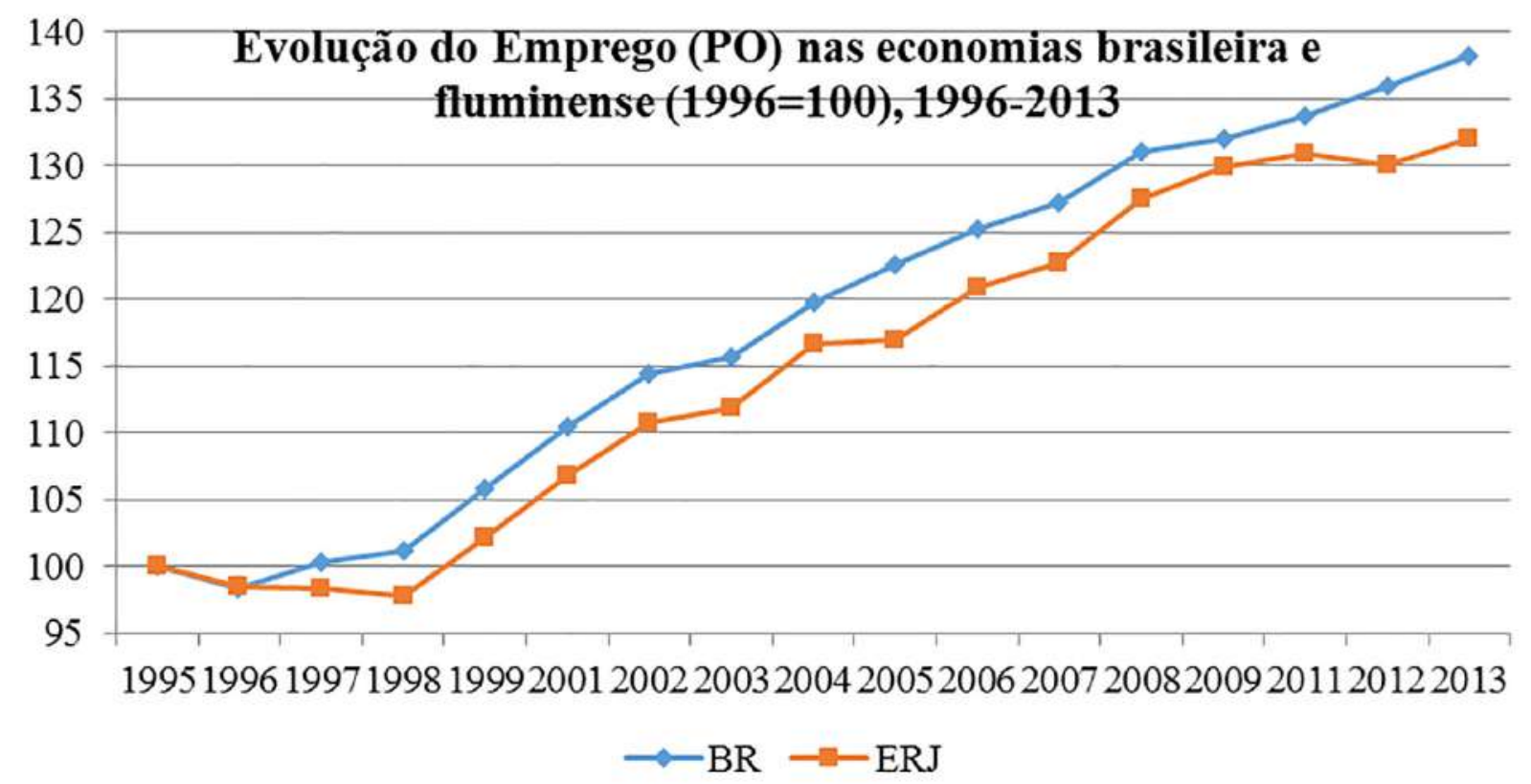

Fonte: IBGE a partir de Ipeadata. 
A alta produtividade de poucos setores na economia, associada ao baixo crescimento do PIB per capita e do emprego, sugerem, também, uma elevada desigualdade nos níveis salariais dos trabalhadores empregados nos diferentes setores. De fato, estudo recente demonstrou que a atividade de extração de petróleo, no ERJ, concentrou, no biênio 2009-2010, quase 16 vezes mais ocupações de altíssima remuneração (acima de 20 salários mínimos) em comparação com a economia fluminense como um todo (HASENCLEVER et al., 2017). Dado que o acesso a esses poucos postos de trabalho é restrito à minoria da população, a desigualdade de renda no ERJ, medida pelo índice de Gini, recuou apenas 9\% entre 1996 e 2014, enquanto no Brasil o recuo foi de $14 \%$. Tal fato fez com que o ERJ se tornasse o quinto estado brasileiro com a pior desigualdade de renda em 2014, enquanto em 1996 sua posição era a décima sexta ${ }^{4}$.

Os dados apontados indicam que o forte desempenho das indústrias baseadas em petróleo no ERJ não foi acompanhado pelos demais setores de atividades, possivelmente por causa de limitações nos efeitos de encadeamento produtivo características de setores extrativos localizados na etapa inicial de cadeias produtivas ${ }^{5}$. Ademais, o estado testemunhou a redução absoluta de segmentos importantes, alguns classificados como de AT, e, portanto, cruciais para o desenvolvimento tecnológico, e outros de BT, intensivos em empregos.

Assim, enquanto, de maneira geral, a economia brasileira demonstrou um padrão de crescimento associado à expansão do emprego e do consumo, com estagnação da produtividade (DE NEGRI; CAVALCANTE, 2014), o ERJ apresentou maior intensidade na especialização da produção extrativa e nas indústrias de bens intermediários, com forte expansão da produtividade nessas indústrias, mas baixa absorção de emprego e menor crescimento econômico. Devido a essas características, pode-se classificar o padrão de desenvolvimento recente do ERJ, nos termos da Cepal (2012), como uma "mudança estrutural limitada a enclaves", enquanto o padrão nacional estaria, nos anos 2000, mais próximo a um padrão de absorção de emprego, caracterizado por uma mudança estrutural "débil".

Uma mudança estrutural limitada a enclaves pode ser vista como insuficiente para garantir um padrão de desenvolvimento sustentável no longo prazo (KATZ, 2000), uma vez que há excessiva especialização produtiva, pouca absorção de emprego e efeitos distributivos regressivos. Nesse tipo de mudança estrutural, apenas poucas atividades se modernizam, de maneira que o emprego e a economia em geral ficam excluídos dos benefícios da difusão tecnológica. A heterogeneidade estrutural, que é uma característica marcante do subdesenvolvimento, tende a se reproduzir e se aprofundar nesse modelo. Isso porque as dificuldades de propagação do progresso técnico reforçam as diferenças intersetoriais de produtividade, reafirmando a coexistência de segmentos altamente produtivos com a grande importância relativa de setores de baixa produtividade. Mediada pelo mercado de trabalho, essa estrutura heterogênea vincula-se a uma alta desigualdade de renda, expressão de fortes assimetrias salariais e de qualificação dos trabalhadores.

Em se tratando de uma especialização produtiva em commodities, como é o caso do ERJ, ficam ainda mais explícitas a fragilidade e a instabilidade desse modelo de desenvolvimento. Como ressalta Cepal (2012), o ciclo de crescimento vivenciado por economias produtoras de recursos naturais nos anos 2000 esteve intimamente associado à melhoria dos termos de troca e aumento do comércio internacional em benefício desses países. Assim, esse ciclo não foi resultado majoritariamente de um processo endógeno de construção de capacidades e adensamento da estrutura produtiva, mas sim uma resposta a novos padrões de demanda mundiais impulsionados principalmente pela China. Esse fato revela a forte vulnerabilidade do ERJ frente a desacelerações da economia mundial e a oscilações dos preços internacionais das commodities, e o desafio de transformar os impulsos exógenos de demanda em um processo endógeno de desenvolvimento. Esses resultados são também corroborados, dentre outros, por Hasenclever et al. (2016) e Sobral (2016).

5 A atividade de extração de petróleo possui um índice de ligação para trás, que é uma medida dos encadeamentos produtivos do setor, de apenas 0,96, o que a coloca na $36^{\mathrm{a}}$ posição dentre 55 atividades, de acordo com os dados de 2005 da matriz de insumo-produto (GUILHOTO; SESSO FILHO, 2010). 


\section{Conclusões}

O objetivo do artigo foi avaliar de que maneira a problemática do subdesenvolvimento se coloca contemporaneamente ao ERJ, tendo em vista ser este o estado lócus do descobrimento das maiores jazidas de petróleo do país.

Como visto, a análise do tecido industrial fluminense indicou que o ERJ possui uma vocação para a produção de bens primário-extrativos e para segmentos industriais de MBT. Em geral, confirmou-se que essa vocação está associada à indústria do petróleo, preponderantemente em sua etapa extrativa, mas também em setores da indústria de transformação, como o refino, a produção de derivados e segmentos da indústria química. Em termos de categoria de uso, o ERJ é um grande fornecedor de bens intermediários.

Nesse sentido, argumenta-se que o estado aumentou sua dependência de segmentos associados ao petróleo, abrindo mão tanto de atividades tradicionais - geralmente intensivas em mão de obra -, como de atividades de ponta, importantes para o desenvolvimento tecnológico.

Quando analisados os dados referentes à produtividade do trabalho, constata-se que, entre $1996 \mathrm{e}$ 2013, houve forte expansão desse indicador em nível regional e estagnação ou mesmo recuo em nível nacional. Apesar de aumentos de produtividade sugerirem processos de catching up e convergência com níveis tecnológicos de países desenvolvidos, não parece ser este o caso da economia fluminense. Isso porque o maior nível de produtividade estadual não decorreu de um fenômeno generalizado de crescimento da eficiência produtiva associado à diversificação das atividades e ganho relativo de importância de segmentos intensivos em conhecimento e tecnologia. De fato, diferentemente do que ocorre em processos típicos de desenvolvimento, em que há uma retroalimentação positiva entre crescimento, produtividade, diversificação e emprego, o que houve no ERJ foi um aumento da concentração e especialização industrial, baixo crescimento econômico e baixa geração de empregos.

Nesse sentido, os diferentes dados apresentados permitem afirmar que o ERJ e o Brasil descreveram padrões de desenvolvimento distintos. Enquanto a economia brasileira demonstrou um padrão de desenvolvimento associado à expansão do emprego e do consumo, com crescimento da demanda agregada, mas estagnação ou mesmo recuo da produtividade, caracterizando uma mudança estrutural débil, a economia fluminense seguiu outro caminho, ainda que igualmente frágil e incapaz de se sustentar no longo prazo.

O padrão de desenvolvimento estadual pode ser caraterizado como uma mudança estrutural limitada a enclaves, centrado na indústria do petróleo com forte especialização produtiva e aumento de produtividade, mas poucos encadeamentos e transbordamentos. Esse tipo de mudança estrutural é visto como insuficiente para garantir um padrão de desenvolvimento sustentável no longo prazo, estando sujeito a fragilidades internas e a flutuações internacionais de preços e de demanda.

As evidências apresentadas corroboraram, portanto, que a especialização produtiva fluminense, a despeito de seu impacto positivo sobre a produtividade agregada da indústria estadual, não tem se constituído em uma via virtuosa de desenvolvimento. Ao contrário, o aumento da importância da indústria extrativa de petróleo no ERJ explicitou uma situação de heterogeneidade estrutural com impactos regressivos sobre a distribuição de renda, baixo crescimento econômico e vulnerabilidade externa. Essas características são sintomáticas de economias subdesenvolvidas e tendem a se reproduzir e se perpetuar ao longo do tempo.

Em relação a futuras pesquisas, é importante avançar nos reflexos desta especialização produtiva na estrutura e pauta de comércio exterior do ERJ para compreender como se dá a distribuição das diferentes etapas produtivas pelo globo e a respectiva geração e apropriação de valor. Essa compreensão é elementar para se construírem políticas locais que, levando em conta a configuração global, ajudem a superar os entraves do subdesenvolvimento. Uma maneira de se avançar nessa direção é a partir de análises do comércio internacional com base no valor adicionado gerado em cada país, o que tem se tornado cada vez mais factível graças ao desenvolvimento de bases de dados internacionais que adotam esse foco (como a Trade in Value Added da OCDE-OMC). 


\section{Referências bibliográficas}

ANP. Boletim da Produção de Petróleo e Gás Natural. Agência Nacional do Petróleo, Gás Natural e Biocombustível. N. 115, março de 2020.

BALASSA, B. Trade Liberalisation and Revealed Comparative Advantage. The Manchester School, 33, pp. 99-123, 1965.

BIELSCHOWSKY, R. (org.). Cinquenta anos de pensamento da CEPAL. Rio de Janeiro: Ed. Record, 2000.

CEPAL. Cambio estructural para la igualdad: Una visión integrada del desarrollo. Trigésimo cuarto período de sesiones de la CEPAL, San Salvador, ago. 2012.

CHANDLER, A. D. Scale and Scope: the dynamics of industrial capitalism. Cambridge: Harvard University Press, 1990.

COLISTETE, R. P. O desenvolvimentismo cepalino: problemas teóricos e influências no Brasil. Estudos Avançados, vol. 15, no. 41, jan./abr. São Paulo: IEA/USP, pp. 21-34, 2001.

DE NEGRI, F.; CAVALCANTE, L. R. Os dilemas e os desafios da produtividade no Brasil. In DE NEGRI, F.; CAVALCANTE, L. R. (org.). Produtividade no Brasil: desempenho e determinantes. Volume 1, Brasília: ABDI, IPEA, pp. 15-51, 2014.

FURTADO, C (1967). Teoria e política do desenvolvimento econômico. São Paulo: Editora Nacional, $4^{\mathrm{a}}$ Ed., 1971.

GUILHOTO, J. J. M.; SESSO FILHO, U. A. Estimação da matriz insumo-produto utilizando dados preliminares das contas nacionais: aplicação e análise de indicadores econômicos para o Brasil em 2005. Economia \& Tecnologia, Curitiba, v. 23, out./dez., pp. 53-62, 2010.

GYLFASON, T. Natural resources and economic growth: from dependence to diversification. In: Sustainable Economic Liberalization and Integration Policy: Options for Eastern Europe and Russia, University of Wuppertal, Germany, 2004.

HASENCLEVER, L.; CAVALIERI, H.; TORRES, R.; MENDES, H. Especialização produtiva: potenciais e desafios para o estado do Rio de Janeiro. Cadernos do Desenvolvimento Fluminense, n. 10 , p. 40-52, 2016.

HASENCLEVER, L.; MENDES, H.; CAVALIERI, H. Especialização em Recursos Naturais e Emprego no Brasil: o caso do petróleo no Rio de Janeiro. In: Riqueza de recursos naturales: ¿ riqueza de empleos? Revisitando la evidencia en América del Sur. Red Sudamericana de Economía Aplicada/ Red Sur, 2017. Disponível em: https://www.redsudamericana.org/recursos-naturales-desarrollo?page $=1$. Acesso em 12/05/2020.

HIRSCHMAN, A. O. The Strategy of Economic Development, New Haven: Yale University Press, 1958.

IBGE. Classificação por Grandes Categorias Econômicas. Rio de Janeiro: Instituto Brasileiro de Geografia e Estatística, 2013.

IBGE. Pesquisa Industrial Anual - Empresa. Rio de Janeiro: Instituto Brasileiro de Geografia e Estatística, Série Relatórios Metodológicos, v. 26, 2004.

KALDOR, N. (1966). Causes of the Slow Rate of Economic Growth in the United Kingdom, in: Kaldor, N. Further Essays on Economic Theory, New York, Holmes \& Meier, 1978.

KATZ, J. El nuevo modelo economico latinoamericano: aspectos de eficiencia y equidad que questionan su sustentabilidad de largo plazo. Research Report NT10 - RedeSist. Mimeo, 2000.

OCDE. ISIC Rev. 3 Technology intensity definition: Classification of manufacturing industries 
into categories based on R\&D intensities. Organisation for Economic Co-operation and Development: Directorate for Science, Technology and Industry - Economic Analysis and Statistics Division, Jul. 2011.

PENROSE, E. (1959). A Teoria do Crescimento da Firma. Campinas, SP: Editora da Unicamp, 2006.

PEREIRA, L.V. As exportações fluminenses - a maldição dos recursos naturais? In: PINHEIRO, A. C.; VELOSO, F. (Org.). Rio de Janeiro: um estado em transição. Rio de Janeiro: Editora FGV, pp.149-178, 2012.

PEREZ, C. (2010). Dinamismo tecnológico e inclusión social em América Latina: una estrategia de desarrollo productivo basada en los recursos naturales. Revista CEPAL, Santiago, v. 100, n. 2, pp. 123-145, abr.

SANTOS, C. Indústria automobilística no Rio cresce, mas ainda é pequena. Valor Online, 11 out. 2011. Disponível em: <http://www.valoronline.com.br>. Acesso em 04 abr. 2016.

SOBRAL, B. A Falácia da "inflexão econômica positiva": algumas características da desindustrialização fluminense e do "vazio produtivo" em sua periferia metropolitana. Cadernos do Desenvolvimento Fluminense, n. 10, pp. 9-28, 2016. 